\title{
Music therapy in rehabilitation
}

\author{
Joanna Strzemecka ${ }^{1,2}$ \\ 1 Pope John Paul II State School of Higher Education in Biała Podlaska, Institute of Public Health, Poland \\ 2 Departament of Rehabilitation and Orthopaedics, Medical University of Lublin, Poland
}

Strzemecka J. Music therapy in rehabilitation. J Pre-Clin Clin Res. 2013; 7(1): 19-22.

\begin{abstract}
Music now plays an increasing role in several disparate areas. Music therapy appears to affect physiological phenomen such as blood pressure, heart beat, respiration, and mydriasis as well as emotional aspects such as mood and feelings. It is used in the rehabilitation of patients with dementia, Parkinson's disease, fibromyalgia, stroke, aphasia and visual rehabilitation. Music in the patient with dementia produced significantly higher levels of interest and pleasure than the baseline condition. In accordance with the clinical literature, it may be argued that the Music Therapy-induced improvement in bradykinesia could be due to the effect of external rhythmic cues, which, acting as a timekeeper, may stabilize the internal rhythm formation process in patients with Parkinson's disease. In fibromyalgia was to investigate the effects of sleep and touch therapy accompanied by music and aromatherapy on the symptoms of fibromyalgia and depression. In stroke rehabilitation, elements of music have previously been used as a part of physiotherapy and speech therapy to enhance the recovery of motor and speech functions. One of the few accepted treatments for severe, nonfluent aphasia is Melodic Intonation Therapy (MIT), a treatment that uses the musical elements of speech (melody \& rhythm) to improve expressive language by capitalizing on preserved function (singing) and engaging language-capable regions in the undamaged right hemisphere. Mozart's Sonata for Two Pianos was used to visual rehabilitation. The following paper is based on information obtained from the literature review on the use of music therapy in rehabilitation. Conclusion: The use of music therapy in the rehabilitation is huge, but little appreciated. Music therapy is a method of cost-effective, non-invasive where it no reported its side effects. There are small number of studies and publications on the use of music as a form of rehabilitation.
\end{abstract}

\section{Key words}

music therapy, rehabilitation, disease

\section{INTRODUCTION}

Music now plays an increasing role in several disparate areas. Music can reduce stress, improve athletic performance, improve motor function in neurologically impaired patients with stroke or Parkinsonism [1]. Moreover, patients who listened to music also experienced less depressed and, to a lesser extent, confused mood after the intervention than patients who received no listening material. Since the patient groups did not differ in demographic and clinical variables at the baseline or in antidepressant medication and rehabilitation received during the intervention, and since any non-specific effects of therapeutic attention were controlled for, these differences observed in cognitive recovery can be directly attributed to the effect of listening to music [2]. Music therapy appears to affect physiological phenomena such as blood pressure, heart beat, respiration, and mydriasis as well as emotional aspects such as mood and feelings [3, 4, 5]. Clinical studies in adults also demonstrated correlations between the physiological and emotional stimulation effects of music $[4,5]$. Music has been used as a form of therapy for many different diseases and, unless hearing is totally affected, may indeed be experienced and appreciated by even the most severely physically or cognitively impaired subjects [6]. Music Therapy has been widely used in the rehabilitation of handicapped children, providing one of the few ways in which these subjects can attain self-expression [7]. In addition, Music Therapy is recommended in geriatric care to

Address for correspondence: Joanna Strzemecka, Departament of Rehabilitation and Orthopaedics, Medical University of Lublin, Jaczewskiego 8, 20-954 Lublin, Poland

e-mail: joannastrzemecka@wp.pl

Received: 10 May 2013; accepted: 19 June 2013 improve the social, psychological, intellectual, and cognitive performance of older people $[8,9]$. Depressed older adults, in particular, can experience the effects of passive Music Therapy $[10,11]$. Finally, anecdotal evidence and clinical studies show that Music Therapy improves the cognitive functions and quality of life of patients with Alzheimer's disease $[12,13,14,15]$.

Dementia. According to the World Health Organization report published in 2012, the estimated number of people living with dementia exceeds 35.6 million worldwide (Alzheimer's Disease International, 2009). This number is predicted to double by 2030 , and more than triple by 2050 (Alzheimer's Disease International, 2009).0ur results concerning music are of note, as we found that music produced low levels of interest and pleasure in comparison to other stimuli [16]. To our knowledge, there are no other studies of music that utilize pleasure as a specific outcome measure in this population. Several studies have linked music to a decrease in agitation and/or apathy in persons with dementia $[17,18,19]$, and an increase in positive social behaviors [20]. Gotell et all found that music increased awareness of and interest in their environment in persons with dementia [21]. Our results agree with those findings in that music produced significantly higher levels of interest and pleasure than the baseline condition [22].

Alzheimer's disease (AD), the most common form of dementia, is characterized by a general, progressive decline in cognitive function that typically presents first as impaired episodic memory. The main goal of the present study was to determine the extent to which music can be used to enhance memory for associated verbal information in patients with $\mathrm{AD}$ and healthy older adults. The results confirmed our 
hypothesis that patients with $\mathrm{AD}$ performed better on a task of recognition memory for the lyrics of songs when those lyrics were accompanied at encoding by a sung recording than when they were accompanied by a spoken recording. Musical mnemonics provide an intricate neurophysiologic template for the mapping of verbal information in temporal and tonal space, and this template may be used during retrieval to aid in lyric recognition or recall. For healthy older adults with intact cortical memory circuits, it is possible that the relatively simple nature of the recognition task in the current paradigm does not produce a need to recruit from these areas of the brain not typically used for recognition memory, and so results in no difference between the sung and spoken conditions. In other words, there may be no need to rely on the holistic musical memory "backup" at the part of the performance scale where control subjects scored [23]. It is also possible that attentional deficits in patients with $\mathrm{AD}$ [24] and the ability of music to moderate these deficits by heightening arousal [25], account for the effect of condition in the patient group [23].

Parkinson's Disease. Parkinson's Disease (PD) is a common degenerative disease dominated by a disorder of movement, consisting of bradykinesia (slowness of movement), hypokinesia (reduced movements), tremor, rigidity, and postural and gait abnormalities; mood changes are also a major component of PD [26]. This study is the first to assess objectively the effect of a systematic program of active Music Therapy on standardized measures of PD severity using a prospective, single-blinded design. Moreover, this randomized, controlled clinical study compared the efficacy of Music Therapy and Physical Therapy to highlight any eventual difference between the two methods in their effect on both physical and emotional functions. Our results demonstrate improvements in motor abilities and emotional status related to active Music Therapy. The improvement in motor performance was related mainly to changes in bradykinesia. Although the Music Therapy-related motor response seemed to decline after each session, a trend of improvement was observed in the Music Therapy group in the overall evaluation. Improvement in emotional functions was found both after each Music Therapy session and throughout the entire study period, but when measured 2 months after completion of Music Therapy, the values returned to baseline levels. Significant improvements in ADL and quality of life were also documented in patients undergoing Music Therapy. Physical Therapy, meanwhile, led to a clear improvement in rigidity but did not induce any major changes in other variables [27]. In accordance with the clinical literature, it may be argued that the Music Therapy-induced improvement in bradykinesia could be due to the effect of external rhythmic cues, which, acting as a timekeeper, may stabilize the internal rhythm formation process in patients with PD [27, 28, 29, $30]$. This motor power of rhythm may be especially strong in various forms of motor and impulse disorder-and music can indeed be therapeutic here. Thus, patients with parkinsonism, in whom movements tend to be incontinently fast or slow or sometimes frozen, may overcome these disorders of timing when they are exposed to the regular tempo and rhythm of music [31].

Fibromyalgia. Fibromyalgia is a chronic disease characterized by sensitive points on the body that manifest common musculoskeletal pains, fatigue, and low pain threshold. Although there is no clear-cut data about the prevalence and incidence of FMS in the world, prevalence is generally between $6 \%$ and $20 \%[32,33]$. The aim of the study Demirag et all [33] was to investigate the effects of sleep and touch therapy accompanied by music and aromatherapy on the symptoms of fibromyalgia and depression, and the findings are as follows (These results support the study hypotheses): The TMA(touch therapy accompanied by music and aromatherapy) intervention reduced FMS symptoms in patients, and the change is statistically significant. The SMA (sleep accompanied by music and aromatherapy) intervention reduced FMS symptoms in patients, and the change is statistically significant. The education given to the patients in both the TMA and SMA groups during the intervention was effective in decreasing the symptoms [33].

Visual rehabilitation. Salvatore et all in publication describes a 74-year-old patient with open angle glaucoma in both eyes and macular pucker in the right eye (RE) underwent visual rehabilitation with acoustic biofeedback by means of the MAIA $^{\mathrm{m}}$ Vision Training Module (Centervue, Padova, Italy) 10 minutes each eye once a week for 5 weeks. The patient was asked to move his eyes according to a sound which changed into Mozart's Sonata for Two Pianos when the patient locked the fixation target. This is the first time that Mozart music has been applied to a visual rehabilitation, and the results are worthy of attention. Music could enhance synaptic plasticity in the brain and affect neural learning and fixation training. By means of MAIA, we can improve the visual performance in patients with macular pucker to postpone the surgical time and assure the patient a better quality of life [34].

Stroke. During the first weeks and months of recovery after a stroke, the brain can undergo dramatic plastic changes $[35,36]$ that can be further enhanced by stimulation provided by the environment.In stroke rehabilitation, elements of music have previously been used as a part of physiotherapy [37] and speech therapy [38] to enhance the recovery of motor and speech functions. In addition, nonverbal auditory stimuli have been shown to temporarily ameliorate left visual neglect after stroke [39]. However, the knowledge about the long-term effects of everyday music listening itself on the recovery of cognitive and emotional functions after stroke is very limited [2]. Musical training has extensive effects on the brain. One aspect that may be relevant for stroke rehabilitation is that musicians have enhanced subcortical auditory and audiovisual processing of speech and music $[40,41,42]$. In the study, authors have observed significant motor gains accompanied by plastic changes in chronic stroke patients who were tested before and after 20 sessions of music supported therapy (MST). Of note, they found increased motor cortex excitability in the patients' affected hemisphere after training, an association between changes in the motor cortex representation on the injured hemisphere and improved performance of diadochokinetic movements with the affected upper limb. These results suggest that MST can drive task-dependent cortical reorganization in stroke patients in the chronic stage [43].

Kim et all in their publication describe in conclusion: 'Music therapy has a positive effect on mood in post-stroke patients and may be beneficial for mood improvement with stroke'. These results are encouraging, but further studies 
are needed in this field. In their investigation psychological status was evaluated with the Beck Anxiety Inventory (BAI) and Beck Depression Inventory (BDI) before and after music therapy. Satisfaction with music therapy was evaluated by a questionnaire. Results: BAI and BDI scores showed a greater decrease in the music group than the control group after music therapy, but only the decrease of BDI scores were statistically significant $(\mathrm{p}=0.048)$. Music therapy satisfaction in patients and caregivers was affirmative [5].

Aphasia. According to the National Institutes for Health (NINDS Aphasia Information Page: NINDS, 2008), approximately 1 in 272 Americans suffer from aphasia, a disorder characterized by the loss of ability to produce and/ or comprehend language. Despite its prevalence, the neural processes that underlie recovery remain largely unknown and thus, have not been specifically targeted by aphasia therapies. One of the few accepted treatments for severe, nonfluent aphasia is Melodic Intonation Therapy (MIT), $[44,45,46,47,48,49]$ a treatment that uses the musical elements of speech (melody \& rhythm) to improve expressive language by capitalizing on preserved function (singing) and engaging language-capable regions in the undamaged right hemisphere. In speech, phonemes occur so quickly it is difficult for severely aphasic and/or apraxic patients to process auditory feedback in time to self-correct. However, when words are sung, phonemes are isolated and thus, can be heard distinctly while still connected to the word. In addition, sustained vowel sounds provide time to "think ahead" about the next sound, make internal comparisons to the target, and self-correct when sounds produced begin to go awry [49]. Recovery from aphasia can happen in two ways: either through the recruitment of perilesional brain regions in the affected hemisphere, with variable recruitment of right- hemispheric regions if the lesion is small, or through the recruitment of homologous language and speech-motor regions in the unaffected hemisphere if the lesion of the affected hemisphere is extensive. Treatment-associated neural changes in patients undergoing MIT indicate that the unique engagement of right-hemispheric structures (e.g., the superior temporal lobe, primary sensorimotor, premotor and inferior frontal gyrus regions) and changes in the connections across these brain regions may be responsible for its therapeutic effect [50].

\section{CONCLUSIONS}

The use of music therapy in the rehabilitation is huge, but little appreciated. Music therapy is a method of cost-effective, non-invasive where it no reported its side effects. There are small number of studies and publications on the use of music as a form of rehabilitation.

\section{REFERENCES}

1. Sleight P. Cardiovascular effects of music by entraining cardiovascular autonomic rhythms music therapy update: tailored to each person, or does one size fit all? Neth Heart J. 2013; 21(2): 99-100.

2.Särkämö T, Tervaniemi M, Laitinen S, Forsblom A, Soinila S, Mikkonen M, Autti T, Silvennoinen HM, Erkkilä J, Laine M, Peretz I, Hietanen M. Music listening enhances cognitive recovery and mood after middle cerebral artery stroke. Brain. 2008; 131(Pt 3): 866-76. doi: 10.1093/ brain/awn 013
3. Standley JM. Music research in medical/dental treatment: meta- analysis and clinical applications. J Music Ther 1986; 23: 56-122.

4. Peretti PO, Zweifel J. Affect of musical preference on anxiety as determined by physiological skin responses. Acta Psychiatr Belg. 1983; 83: 437-42.

5. Kim DS, Park YG, Choi JH, Im SH, Jung KJ, Cha YA, Jung CO, Yoon YH. Effects of Music Therapy on Mood in Stroke Patients. Yonsei Med J. 2011; 52(6): 977-981.

6. Smith DS. Therapeutic treatment effectiveness as documented in the gerontology literature: implications for music therapy. Music Ther Perspect. 1990; 8: 36-40.

7. Kirk R, Abbotson M, Abbotson R, Hunt A, Cleaton A. Computer music in the service of music therapy: the MIDIGRID and MIDI-CREATOR systems. Med Eng Phys. 1994; 16: 253-8.

8. Gibbons AC. Music development in the elderly: what are the chances? Designs Clin Enhancement. 1986; 81: 24-5.

9. Tyson J. Evaluating elderly diseases. Nursing. 1988; 18: 34-41.

10. Hanser SB, Thompson LW. Effects of a music therapy strategy on depressed older adults. J Gerontol. 1994; 49: P265-9.

11. Smith DS. Therapeutic treatment effectiveness as documented in the gerontology literature: implications for music therapy. Music Ther Perspect. 1990; 8: 36-40.

12. Aldridge D. Music and Alzheimer's disease-assessment and therapy: discussion paper. J R Soc Med. 1993; 86: 93-5.

13. Aldridge D. Alzheimer's disease: rhythm, timing and music therapy. Biomed Pharmacother. 1994; 48: 275-81.

14.Lord TR, Garner JE. Effects of music on Alzheimer patients. Percept Mot Skills. 1993; 76: 451-5.

15. Pacchetti C, Mancini F, Aglieri R, Fundarò C, Martignoni E, Nappi G. Active music therapy in Parkinson's disease: an integrative method for motor and emotional rehabilitation. Psychosom Med. 2000; 62(3): $386-93$.

16. Sakamoto M, Ando H, Tsutou A. Comparing the effects of different individualized music interventions for elderly individuals with severe dementia.Int Psychogeriatr. 2013; 25(5): 775-84.

17. Choi AN, Lee MS, Cheong KJ, et al. Effects of group music intervention on behavioral and psychological symptoms in patients with dementia: a pilot-controlled trial. Int J Neurosci. 2009; 119(4): 471-481.

18. Clark ME, Lipe AW, Bilbrey M. Use of music to decrease aggressive behaviors in people with dementia. J Gerontol Nurs. 1998; 24(7): 10-17.

19. Raglio A, Bellelli G, Traficante D, et al. Efficacy of music therapy in the treatment of behavioral and psychiatric symptoms of dementia. Alzheimer Dis Assoc Disord. 2008; 22(2): 158-162.

20. Ziv N, Granot A, Hai S, et al. The effect of background stimulative music on behavior in Alzheimer's patients. J Music Ther. 2007; 44(4): 329-343.

21. Götell E, Brown S, Ekman SL. Influence of caregiver singing and back-ground music on posture, movement, and sensory awareness in dementia care. Int Psychogeriatr. 2003; 15(4): 411-430.

22. Cohen-Mansfield J, Marx MS, Thein K, Dakheel-Ali M.The impact of stimuli on affect in persons with dementia.J Clin Psychiatry. 2011; 72(4): 480-6.

23. Nicholas R. Simmons-Stern, Andrew E. Budson, and Brandon A. Ally. Music as a Memory Enhancer in Patients with Alzheimer's Disease. Neuropsychologia. 2010 August; 48(10): 3164-3167.

24. Perry RJ, Hodges JR. Attention and executive deficits in Alzheimer's disease. A critical review. Brain 1999; 122(Pt 3): 383-404.

25. Thompson WF, Schellenberg EG, Husain G. Arousal, mood, and the Mozart effect. Psychol Sci 2001;12(3):248-251.

26. Marsden CD. Parkinson's disease. J Neurol Neurosurg Psychiatry. 1994; 57: 672-81.

27. Pacchetti C, Mancini F, Aglieri R, Fundarò C, Martignoni E, Nappi G. Active music therapy in Parkinson's disease: an integrative method for motor and emotional rehabilitation. Psychosom Med. 2000; 62(3): 386-93.

28. Nakamura R, Nagasaki H, Narabayashi H. Disturbances of rhythm formation in patients with Parkinson's disease. Percept Mot Skills 1978; 46: 63-75.

29. Benecke R, Rothwell JC, Dick JPR, Day BL, Marsden CD. Distur- bance of sequential movements in patients with Parkinson's disease. Brain 1987; 110: 361-79.

30. Agostino R, Berardelli A, Formica A, Accornero N, Manfredi M. Sequential arm movements in patients with Parkinson's disease, Huntington's disease and dystonia. Brain 1992; 115: 1481-95.

31. Sacks O. The power of music. Brain. 2006; 129(Pt 10): 2528-32.

32. Doksat MK. Pain and Psychiatry, Konya: Psikiyatri ve Sanat Yayın Evi, Turkey, 2003, pp.:86-119. 
33. Demirbağ B, Erci B. The effects of sleep and touch therapy on symptoms of fibromyalgia and depression. Iran J Public Health. 2012;41(11):44-53. Epub 2012 Nov 1.

34. Salvatore S, Librando A, Esposito M, Vingolo EM. The Mozart effect in biofeedback visual rehabilitation: a case report. Clin Ophthalmol. 2011; 5: 1269-1272.

35. Witte OW. Lesion-induced plasticity as a potential mechanism for recovery and rehabilitative training. Curr Opin Neurol. 1998; 11: 655-62

36. Kreisel SH, Bazner H, Hennerici MG. Pathophysiology of stroke rehabilitation: temporal aspects of neuro-functional recovery. Cerebrovasc Dis. 2006; 21: 6-17.

37. Thaut MH, McIntosh GC, Rice RR. Rhythmic facilitation of gait training in hemiparetic stroke rehabilitation. J Neurol Sci. 1997; 151: 207-12.

38. Belin P, Van Eeckhout P, Zilbovicius M, Remy P, Francois C, Guillaume $S$, et al. Recovery from nonfluent aphasia after melodic intonation therapy: a PET study. Neurology. 1996; 47: 1504-11.

39. Hommel M, Peres B, Pollak P, Memin B, Besson G, Gaio JM, et al. Effects of passive tactile and auditory stimuli on left visual neglect. Arch Neurol. 1990; 47: 573-6.

40. Musacchia G, Sams M, Skoe E, Kraus NM. Musicians have enhanced subcortical auditory and audiovisual processing of speech and music. Proc. Natl. Acad. Sci. U.S.A. 2007; 104: 15894-15898.

41. Musacchia G, Arum L, Nicol T, Garstecki D, Kraus N. Audiovisual deficits in older adults with hearing loss: biological evidence. Ear Hear. 2009; 30: 505-514. doi: 10.1097/AUD.0b013e3181a7f5b7.

42. Johansson BB. Multisensory Stimulation in Stroke Rehabilitation. Front Hum Neurosci. 2012; 6: 60.
43. Amengual JL, Rojo N, Veciana de Las Heras M, Marco-Pallarés J, Grau-Sánchez J, Schneider S, Vaquero L, Juncadella M, Montero J, Mohammadi B, Rubio F, Rueda N, Duarte E, Grau C, Altenmüller E, Münte TF, Rodríguez-Fornells A. Sensorimotor plasticity after musicsupported therapy in chronic stroke patients revealed by transcranial magnetic stimulation._PLoS One. 2013; 8(4): e61883. doi: 10.1371/ journal.pone.0061883. Print 2013.

44. Albert ML, Sparks RW, Helm NA. Melodic intonation therapy for aphasia. Arch Neurol. 1973; 29: 130- 131.

45. Sparks R, Helm N, Albert M. Aphasia rehabilitation resulting from melodic intonation therapy. Cortex. 1974; 10: 303-316.

46. Helm-Estabrooks, N. Albert, ML. Manual of aphasia and aphasia therapy, Chapter 16. Vol. 2nd ed.. Pro-Ed; Austin, TX: 2004. Melodic intonation therapy; p. 221-233.

47. Schlaug G, Marchina S, Norton A. From singing to speaking: why singing may lead to recovery of expressive language function in patients with Broca's aphasia. Music Perception. 2008; 25: 315-323.

48. Marshall N, Holtzapple P. In: Brookshire, RH., editor. Melodic Intonation Therapy: Variations on a Theme; Clinical Aphasiology Conference: 6th Clinical Aphasiology Conference; BRK Publishers. Minneapolis, MN. 1976; p. 115-141.

49. Norton A, Zipse L, Marchina S, Schlaug G. Melodic Intonation Therapy: Shared Insights on How it is Done and Why it Might Help. Ann N Y Acad Sci. 2009 July; 1169: 431-436.

50. Schlaug G, Norton A, Marchina S, Zipse L, Wan CY. From singing to speaking: facilitating recovery from nonfluent aphasia. Future Neurol. 2010; 5(5): 657-665. 